\title{
Macrophage Colony-stimulating Factor Regulates Both Activities of Neutral and Acidic Cholesteryl Ester Hydrolases in Human Monocyte-derived Macrophages
}

\author{
Toshimori Inaba, Hitoshi Shimano, Takanari Gotoda, Kenji Harada, Masako Shimada, \\ Masako Kawamura, Yoshio Yazaki, and Nobuhiro Yamada \\ Third Department of Internal Medicine, Faculty of Medicine, University of Tokyo, Hongo, Tokyo, Japan, 113
}

\begin{abstract}
Macrophage colony-stimulating factor (M-CSF) regulates cholesterol metabolism in vivo and in vitro. We studied the effects of M-CSF on enzyme activities of acidic cholesteryl ester (CE) hydrolase, neutral CE hydrolase, and acyl-coenzyme A:cholesterol acyltransferase (ACAT), all of which are involved in cellular cholesterol metabolism in macrophages. During the differentiation of monocytes to macrophages, these enzyme activities were induced and further enhanced in response to M-CSF. M-CSF (100 ng/ml) enhanced acidic and neutral CE hydrolase and ACAT activities by 3.2-, 4-, and 2.3-fold, respectively, in the presence of acetyl LDL. The presence of acetyl LDL influenced these enzyme activities. ACAT and acidic CE hydrolase activities were increased and neutral $\mathrm{CE}$ hydrolase activity was decreased, indicating that these enzymes are regulated by intracellular cholesterol enrichment. M-CSF increased the ratios of acidic CE hydrolase to ACAT activity and of neutral CE hydrolase to ACAT activity. The results suggest that M-CSF enhances net hydrolysis of CE by stimulating the two CE hydrolases to a greater extent than ACAT, and M-CSF may reduce the rate of atherogenesis. (J. Clin. Invest. 1993. 92:750757.) Key words: macrophage $\bullet$ macrophage colony-stimulating factor $\bullet$ acidic cholesteryl ester hydrolase $\bullet$ neutral cholesteryl ester hydrolase
\end{abstract}

\section{Introduction}

Human macrophage colony-stimulating factor (M-CSF) ${ }^{1}$ of $85 \mathrm{kD}$, which is produced by monocyte-macrophage lineages, endothelial cells, and fibroblasts, promotes growth and differentiation of monocyte-macrophage lineages and activates various functions of mature macrophages through a specific receptor encoded by protooncogene $\mathrm{c}-\mathrm{fms}(1-3)$. In recent studies, we demonstrated that ( $a$ ) M-CSF stimulates the clearance of lipoproteins containing apolipoprotein B-100 via both LDL receptor-dependent and -independent pathways in rab-

Address correspondence to Dr. Nobuhiro Yamada, Third Department of Internal Medicine, Faculty of Medicine, University of Tokyo, Hongo, Tokyo, Japan, 113.

Received for publication 2 September 1992 and in revised form 16 March 1993.

1. Abbreviations used in this paper: ACAT, acyl-coenzyme A:cholesterol acyltransferase; CE, cholesteryl ester; dbcAMP, dibutyryl cAMP; LPDS, lipoprotein-deficient serum; M-CSF, macrophage colony-stimulating factor; TPA, tetradecanoylphorbol acetate.

J. Clin. Invest.

(c) The American Society for Clinical Investigation, Inc.

0021-9738/93/08/0750/08 \$2.00

Volume 92, August 1993, 750-757 bits (4), (b) M-CSF stimulates the secretion of lipoprotein lipase and apolipoprotein $\mathrm{E}$ from macrophages $(5,6)$, and $(c)$ M-CSF stimulates the uptake and degradation of acetylated LDL, cholesterol esterification, and cholesterol efflux in human monocyte-derived macrophages (7). These results suggest that M-CSF is involved in the lipid metabolism of the vascular wall and plays a significant role in the process of atherosclerosis.

Macrophages take up lipoproteins by receptor-mediated endocytosis, which is delivered to lysosomes for degradation $(8,9)$. Lysosomal acidic cholesteryl ester (CE) hydrolase releases free cholesterol from cholesteryl ester (rich in cholesteryl linoleate) (10) and then the free cholesterol is re-esterified in the cytoplasm by acyl-coenzyme A:cholesterol acyltransferase (ACAT). Chemical analyses have shown that cholesteryl oleate is the main subclass of the accumulated cholesteryl ester (11). This is in marked contrast to the fatty acid composition of the cholesteryl ester in circulating LDL rich in cholesteryl linoleate. It has therefore been suggested that accumulated cholesteryl ester is synthesized endogenously by ACAT, a reaction that preferentially uses oleic acid as the reaction cosubstrate. The accumulated cholesteryl ester is not inert, but rather undergoes continual hydrolysis mediated by cytoplasmic neutral CE hydrolase (12). These three enzymes, ACAT and neutral and acidic $C E$ hydrolases, are believed to be responsible for the regulation of cellular cholesterol. In particular, the two hydrolytic enzymes may play an important role in controlling the net efflux of cholesterol in macrophages (13). Recently, we have demonstrated that sustained administration of M-CSF to Watanabe heritable hyperlipidemic rabbits, an animal model for familial hypercholesterolemia, remarkably reduces the accumulation of cholesteryl ester in the aorta (14). An increase in the CE hydrolase activity in macrophages after M-CSF treatment may be the mechanism that explains the reduction in cholesteryl ester accumulation. To further understand the role of M-CSF in the cellular metabolism of cholesterol, we investigated the effects of M-CSF on the activities of CE hydrolases in comparison with ACAT activity in human monocyte-derived macrophages.

\section{Methods}

Materials. $\left[1-{ }^{14} \mathrm{C}\right]$ Oleic acid $(1.11-2.22 \mathrm{GBq} / \mathrm{mmol})$ was purchased from ICN Biomedicals, Inc. (Costa Mesa, CA). Cholesteryl $\left[1-{ }^{14} \mathrm{C}\right]-$ oleate $(2.0 \mathrm{GBq} / \mathrm{mmol})$ and cholesteryl $\left[{ }^{3} \mathrm{H}\right]$ oleate $(1.9 \mathrm{GBq} / \mathrm{mmol})$ were purchased from Du Pont-New England Nuclear (Boston, MA). Recombinant human M-CSF was a purified product obtained from Morinaga Milk Industry Co., Ltd. (Tokyo, Japan) (15). Albumin (Fraction V), dibutyryl cAMP, tetradecanoylphorbol acetate (TPA), coenzyme A, lecithin, and taurocholic acid were obtained from Sigma Chemical Co. (St. Louis, MO). Silica gel G plates were obtained from Merck (Dusseldorf, Germany). Lymphoprep was purchased from Daiichi Pharmaceutical Co. (Tokyo, Japan). Culture dishes and plates 
were obtained from Corning Inc. (Corning, NY). RPMI 1640 medium, FCS, penicillin-streptomycin, and L-glutamine were obtained from GIBCO BRL (Gaithersburg, MD). H89 was obtained from Seikagaku Kogyo Co. (Tokyo, Japan). All other chemicals were of analytical grade. Acetyl LDL was prepared as described previously (7).

Cells. Human monocyte-derived macrophages were prepared by culturing human peripheral monocytes. Monocytes were isolated from the peripheral blood of a normolipidemic healthy donor using the Ficoll-Hypaque gradient method as described previously (16). The separated mononuclear cells were washed three times with PBS and then suspended in RPMI-1640. Cells were plated in $35-\mathrm{mm}$ dishes at a density of $2 \times 10^{6}$ cells $/$ dish. After $2 \mathrm{~h}$ of incubation at $37^{\circ} \mathrm{C}$, nonadherent cells were removed by three washes with PBS. The cells were then placed in fresh medium containing $10 \%$ autologous serum and used as monocyte-derived macrophages after $9 \mathrm{~d}$ of culture (16). For the measurement of enzyme activities, cells were cultured in the presence or absence of human recombinant M-CSF for the indicated days, and incubated with or without medium containing $100 \mu \mathrm{g} / \mathrm{ml}$ acetyl LDL for $24 \mathrm{~h}$ after a 24-h preincubation with lipoprotein-deficient serum (LPDS). Based on the preliminary experiments, it was concluded that macrophages incubated with $100 \mu \mathrm{g} / \mathrm{ml}$ acetyl LDL yield a consistent level of accumulation of cholesterol ester in each experiment.

Acidic CE hydrolase activity. Acidic CE hydrolase activity was determined by the procedure of Haley et al. (17). Cells cultured in 35$\mathrm{mm}$ dishes were washed three times in cold PBS and scraped off dishes into sucrose buffer ( $10 \mathrm{mM}$ Tris- $\mathrm{HCl}$ buffer, $\mathrm{pH} 7.5$, containing 250 $\mathrm{mM}$ sucrose and $0.1 \mathrm{mM}$ EDTA). Homogenates were prepared by sonication using a sonifier (model 250; Branson Ultrasonics Corp., Danbury, CT); $13 \mu \mathrm{M}$ cholesteryl $\left[1-{ }^{14} \mathrm{C}\right]$ oleate served as the substrate suspended in a lecithin/digitonide dispersion. Substrate blanks were run under identical conditions with sucrose buffer in place of the enzyme. The final reaction conditions consisted of cell lysate, $1.27 \mathrm{mM}$ lecithin, $12.7 \mu \mathrm{M}$ cholesteryl oleate, $2.0 \mathrm{mM}$ sodium taurocholate, $0.005 \%$ digitonin, and $50 \mathrm{mM}$ sodium acetate buffer, $\mathrm{pH}$ 3.9. The reaction was terminated after $60 \mathrm{~min}$ at $37^{\circ} \mathrm{C}$, and the unhydrolyzed substrate was extracted by addition of methanol/chloroform/heptane (1.4:1.3:1.0 vol/vol), followed by the addition of $50 \mathrm{mM}$ borate buffer ( $\mathrm{pH} \mathrm{10.0)}$. The mixture was then agitated and centrifuged to separate the phases. The amount of $\left[{ }^{14} \mathrm{C}\right]$ oleate in the aqueous phase was quantitated by scintillation counting of $500 \mu \mathrm{l}$ of supernatant. Aliquots of the cell homogenate were assayed for protein (18); acidic CE hydrolase activity is expressed as nanomoles of cholesteryl $\left[1-{ }^{14} \mathrm{C}\right]$ oleate hydrolyzed per milligram of cell protein.

The expression of mRNA was studied as described previously (15). The 467-bp fragment of the human acidic CE hydrolase cDNA was prepared by reverse transcription coupled with PCR amplification with two oligonucleotide primers (sense: 5'-ACAGATCCCTGAGCTGGCTA-3', antisense: 5'-TCCAGACTGCAGTCGGCACA-3') that were synthesized according to the published sequence of the human acidic CE hydrolase gene (19), and then was subcloned into the pBluescript II KS (20).

Neutral cholesteryl ester hydrolase activity. Neutral CE hydrolase activity was assayed according to the method of Hajjar et al. (21), which is essentially the same as that described for the acidic CE hydrolase, with the following modifications: the principal components of the final reaction mixture $(425 \mu \mathrm{l})$ were cell lysate, $23.7 \mu \mathrm{M}$ lecithin, 6.0 $\mu \mathrm{M}$ cholesteryl oleate, $12.5 \mu \mathrm{M}$ sodium taurocholate, $0.04 \% \mathrm{BSA}$, and $85 \mathrm{mM}$ potassium phosphate buffer, $\mathrm{pH}$ 7.0. The reaction was initiated by the addition of $75 \mu \mathrm{l}$ of cell lysate in sucrose buffer prepared as mentioned above. The incubation conditions, as well as extraction and quantitation, were similar to the acidic $\mathrm{CE}$ hydrolase assay.

Next, we estimated the neutral $C E$ hydrolase activity by measuring the hydrolysis of stored cholesterol ester in macrophages in the presence or absence of M-CSF, exactly according to the method of Brown et al. (22). Human monocytes were cultured for $7 \mathrm{~d}$ and then incubated with medium containing $50 \mu \mathrm{g} / \mathrm{ml}$ acetylated $\mathrm{LDL}$ and $0.2 \mathrm{mM}$ $\left[{ }^{3} \mathrm{H}\right.$ ] oleate-albumin. After $24 \mathrm{~h}$ at $37^{\circ} \mathrm{C}$, each monolayer was washed and incubated with the same medium in the absence of lipoproteins for another $24 \mathrm{~h}$. After washing monolayers, cells were cultured for the indicated hours without $\left[{ }^{3} \mathrm{H}\right]$ oleate-albumin and the cellular content of cholesteryl $\left[{ }^{3} \mathrm{H}\right]$ oleate was determined by thin layer chromatography and scintillation counting.

Acyl-coenzyme A: cholesterol acyltransferase activity. Enzyme activity was assayed by a modification of the method of Brown et al. (13). Cell-free extracts were prepared by suspending the pellet of macrophages from $35-\mathrm{mm}$ dishes in $1 \mathrm{ml}$ of $20 \mathrm{mM}$ potassium phosphate buffer, $\mathrm{pH} 7.4$, containing $2 \mathrm{mM}$ dithiothreitol and then the suspension was sonicated using a sonifier (model 250; Branson Ultrasonics Corp.). $100 \mu \mathrm{l}$ of the cell extracts was incubated in $200 \mu \mathrm{l}$ of $50 \mathrm{mM}$ potassium

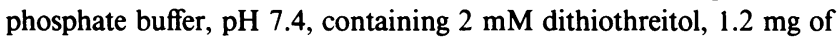
coenzyme $\mathrm{A}$, and $100 \mu \mathrm{M}\left[1-{ }^{14} \mathrm{C}\right]$ oleate-albumin $(10,000 \mathrm{cpm} / \mathrm{nmol})$. After incubation at $37^{\circ} \mathrm{C}$ for $1 \mathrm{~h}$, the reactions were terminated by addition of $4 \mathrm{ml}$ of chloroform/methanol (2:1), and the cholesteryl $\left[{ }^{14} \mathrm{C}\right]$ oleate was isolated by thin layer chromatography and quantified as described previously (7). Enzyme activity is expressed as nanomoles of cholesteryl $\left[{ }^{14} \mathrm{C}\right]$ oleate formed per hour per milligram of total extract protein.

Measurement of cAMP content. Human monocytes were cultured in RPMI 1640 medium containing 10\% FCS in 12-well plates for $7 \mathrm{~d}$ in the absence of M-CSF. $24 \mathrm{~h}$ after incubation with serum-free medium, the cells were further cultured in the presence of $100 \mathrm{ng} / \mathrm{ml} \mathrm{M-CSF}$ for the indicated hours, and $1 \mathrm{mM} 1$-methyl-3-isobutyl xanthine was added to the culture medium 20 min before the addition of M-CSF. Thereafter, the cells were washed three times with ice-cold PBS, and then $500 \mu$ lice-cold isotonic buffer containing $10 \mathrm{mM}$ Tris- $\mathrm{HCl}, 250$ $\mathrm{mM}$ sucrose, and $1 \mathrm{mM}$ EDTA, $\mathrm{pH} 7.3$, was added. The cells were scraped using a rubber policeman, and $930 \mu \mathrm{l}$ ice-cold ethanol (final $65 \%$ ) was added. After the mixtures were centrifuged at $2,000 \mathrm{~g}$ for 15 $\min$ at $4^{\circ} \mathrm{C}$, the extracts were evaporated under a stream of nitrogen at $60^{\circ} \mathrm{C}$ and the resultant dried extracts were dissolved in $500 \mu \mathrm{l}$ buffer containing $50 \mathrm{mM}$ acetate and $0.01 \%$ sodium azide, $\mathrm{pH} 5.8$ (assay samples). cAMP contents of samples $(100 \mu \mathrm{l})$ were measured by the method described in the instructions of the cAMP $\left[{ }^{125} \mathrm{I}\right]$ assay system (Amersham International, Amersham, UK).

Lipid extraction and cholesterol analysis. After a 24-h preincubation with LPDS, the cells were incubated with acetyl-LDL for $24 \mathrm{~h}$ at $37^{\circ} \mathrm{C}$. After exposure to loading medium for $24 \mathrm{~h}$, the cells were washed three times with PBS and then incubated in a medium consisting of RPMI 1640 medium containing cholesterol acceptor. After the indicated hours of incubation, cells were placed on ice and washed three times with cold PBS. Thereafter, the cellular cholesteryl ester was measured as described previously (7).

\section{Results}

Cholesteryl ester hydrolase activity. The activities of both acidic and neutral CE hydrolases were increased linearly during the first 7-9 $\mathrm{d}$ of cell differentiation of human monocytes to macrophages in the presence or absence of either acetyl LDL or M-CSF (Fig. 1). In the presence of acetyl LDL $(100 \mu \mathrm{g} / \mathrm{ml})$, the enzyme activity of acidic $\mathrm{CE}$ hydrolase was 2.1 -fold that of neutral CE hydrolase ( $4.03 \mathrm{vs} 1.96 \mathrm{nmol} / \mathrm{h}$ per mg cell protein), and M-CSF enhanced enzyme activities of both neutral and acidic $C E$ hydrolases to 4.0 - and 3.3-fold that without $M$ CSF on the ninth day of the cell culture, respectively (Fig. 1). In the absence of acetylated LDL, acidic CE hydrolase activity was less than that in the presence of acetylated LDL (2.41 vs $4.03 \mathrm{nmol} / \mathrm{h}$ per $\mathrm{mg}$ cell protein) and neutral CE hydrolase activity was greater than that in the presence of acetylated LDL $(4.35 \mathrm{vs} 1.96 \mathrm{nmol} / \mathrm{h}$ per $\mathrm{mg}$ cell protein). Both activities were enhanced 1.8- and 2.9-fold, respectively, in response to M-CSF on the ninth day of the culture (Fig. 1). When we evaluated the dose-related effect of M-CSF on CE hydrolase activity on the 

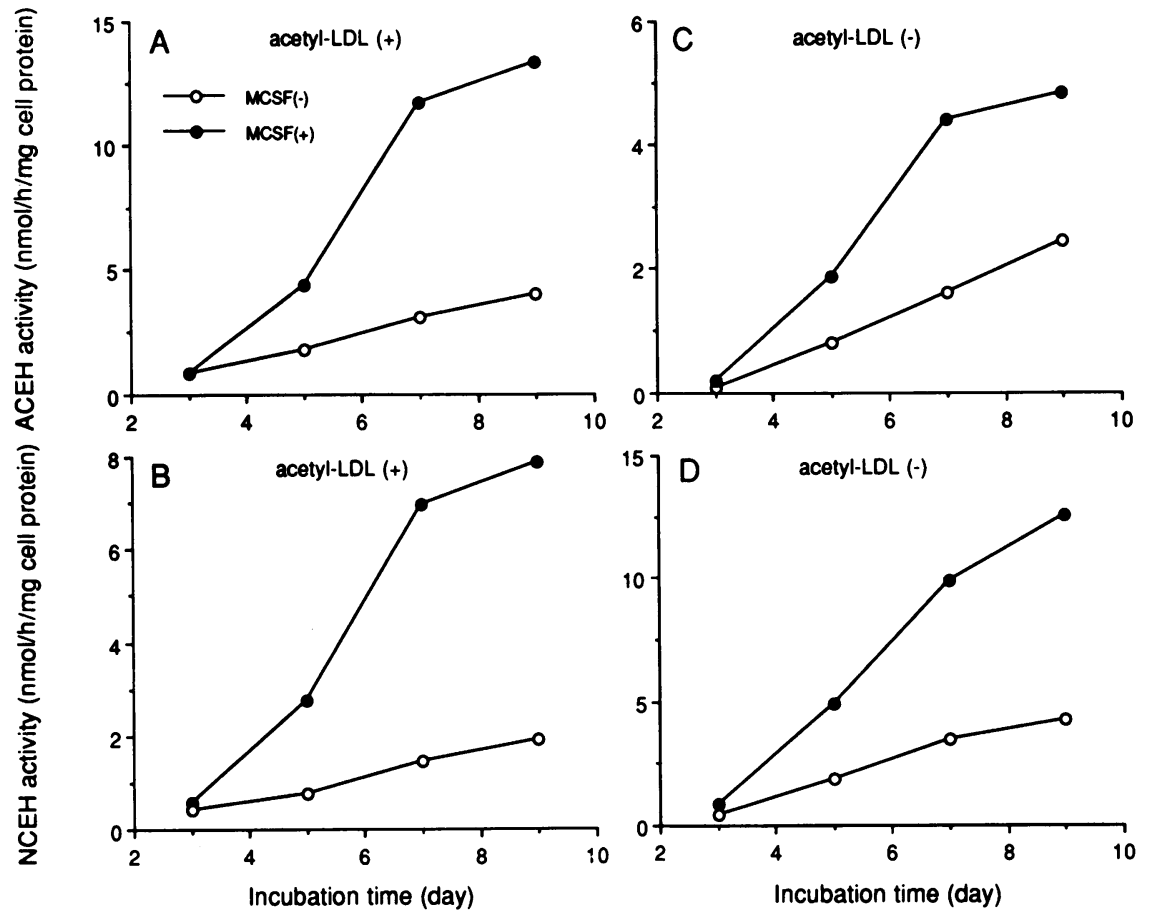

Figure 1. Time-related changes in acidic and neutral cholesteryl ester hydrolase activities in the presence or absence of acetyl LDL, and the effects of human M-CSF on hydrolase activities. Human monocytes were cultured in medium containing $10 \%$ autologous serum with or without $100 \mathrm{ng} / \mathrm{ml} \mathrm{M-CSF}$. The medium was replaced every $3 \mathrm{~d}$. Cells were preincubated with medium containing $5 \mathrm{mg} / \mathrm{ml}$ LPDS for $24 \mathrm{~h}$ before incubation with acetyl LDL ( $A$ and $B$ ). At $24 \mathrm{~h}$ before the time indicated on the abscissa, the medium was replaced by medium containing $100 \mu \mathrm{g} / \mathrm{ml}$ acetyl LDL $(A$ and $B$ ) or $5 \mathrm{mg} / \mathrm{ml}$ LPDS ( $C$ and $D$ ). After $24 \mathrm{~h}$ of incubation at $37^{\circ} \mathrm{C}$, cells were scraped into sucrose buffer and sonicated. Cell homogenates were assayed for acidic and neutral CE hydrolases. Enzyme activity is expressed as nanomoles of substrate hydrolyzed per hour per milligram cell protein. Data represent the means of two different experiments, and each experiment was performed in triplicate.

ninth day of culture, both neutral and acidic CE hydrolase activities were dose dependently increased by M-CSF (Fig. 2). In addition, the time-related effects of $100 \mathrm{ng} / \mathrm{ml} \mathrm{M-CSF}$ on $\mathrm{CE}$ hydrolase activities were determined in the absence of acetylated LDL in differentiated macrophages that had been cultured without M-CSF for $9 \mathrm{~d}$. Both hydrolase activities were not influenced during the first $24 \mathrm{~h}$, and then were significantly enhanced $72 \mathrm{~h}$ after the addition of M-CSF (Fig. 3). In the assay for the estimation of the hydrolysis of stored cholesterol $\left[{ }^{3} \mathrm{H}\right]$ oleate in macrophages that had been cultured with or without M-CSF for $8 \mathrm{~d}$, we observed that M-CSF enhanced an efflux of the cellular cholesterol $\left[{ }^{3} \mathrm{H}\right]$ oleate during the $24-\mathrm{h}$ incubation period. In the presence of $50 \mu \mathrm{g} / \mathrm{ml} \mathrm{HDL}$, the effect of M-CSF was significant as compared with that in the absence of HDL (Fig. 4).

Furthermore, we evaluated mRNA levels of acidic CE hydrolase on the ninth day of culture. In response to $100 \mathrm{ng} / \mathrm{ml}$ M-CSF or $100 \mu \mathrm{g} / \mathrm{ml}$ acetylated LDL, mRNA of acidic CE hydrolase was significantly induced $48 \mathrm{~h}$ after culture of human monocyte-derived macrophages (Fig. 5). The mRNA level of human $\beta$-actin was similar in each preparation, as shown in Fig. 5.

$A C A T$ activity. During the differentiation of monocytes to macrophages, the enzyme activity of ACAT gradually increased and the maximal activity was observed on the seventh to ninth day of cell culture as shown in Fig. 6. The enzyme activity was enhanced by the presence of acetyl LDL, and was increased 3.0- and 2.5 -fold by $100 \mathrm{ng} / \mathrm{ml} \mathrm{M}$-CSF in the presence and absence, respectively, of $100 \mu \mathrm{g} / \mathrm{ml}$ acetyl LDL on the ninth day of culture (Fig. 6). As with the CE hydrolase activities, the effect of M-CSF on ACAT activity was dose related, as shown in Fig. 6. The time-related effect of $100 \mathrm{ng} / \mathrm{ml}$ M-CSF on ACAT activity in the absence of acetylated LDL in differentiated macrophages was also similar to the effect on $\mathrm{CE}$ hydrolase activity (Fig. 3).

As the three enzyme activities were measured in identical cells, it is possible to evaluate the net effects of M-CSF on

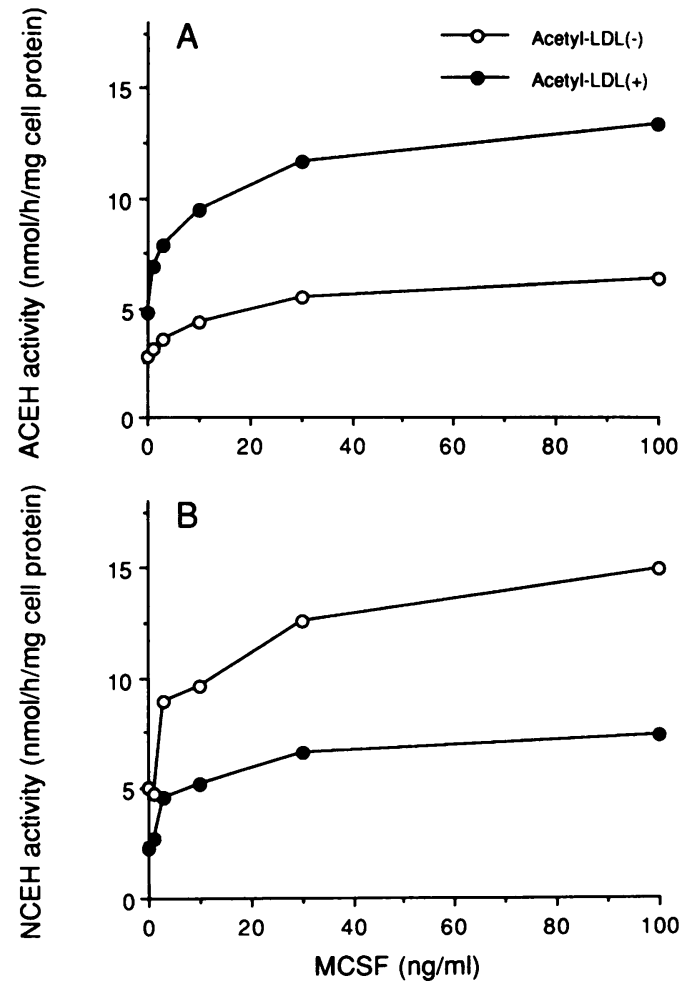

Figure 2. Effects of M-CSF on acidic (top) and neutral (bottom) cholesteryl ester hydrolase activities in the presence or absence of acetyl LDL. Human monocytes were cultured in medium containing $10 \%$ autologous serum with the indicated amounts of M-CSF for $9 \mathrm{~d}$. The medium was replaced every $3 \mathrm{~d}$. Cells were preincubated with medium containing $5 \mathrm{mg} / \mathrm{ml}$ LPDS for $24 \mathrm{~h}$, and then incubated with or without $100 \mu \mathrm{g} / \mathrm{ml}$ acetyl LDL for $24 \mathrm{~h}$. After $9 \mathrm{~d}$ of culture, cells were scraped into sucrose buffer and sonicated. Cell homogenates were assayed for acidic and neutral CE hydrolases. Enzyme activity is expressed as nanomoles of substrate hydrolyzed per hour per milligram cell protein. Data represent the means of two different experiments, and each experiment was performed in duplicate. 

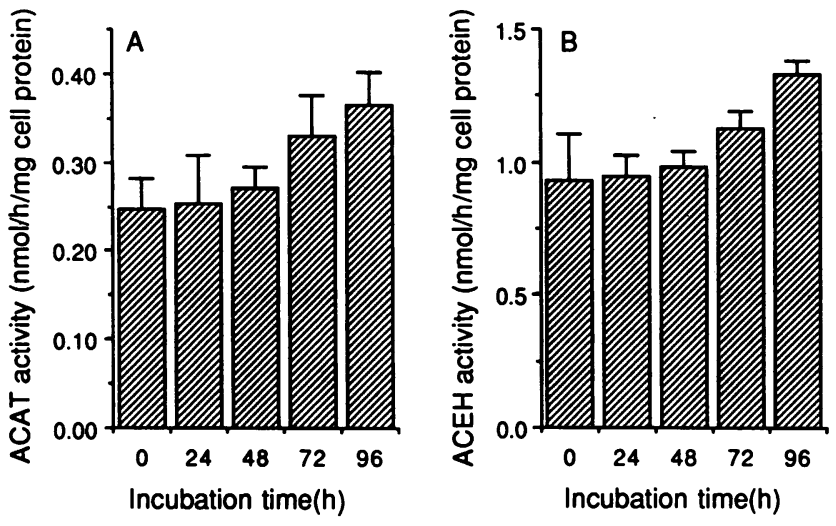

cellular cholesterol metabolism by calculating the ratio of $\mathrm{CE}$ hydrolase activity to ACAT activity. As shown in Fig. 7, MCSF increased the ratio 4.1-fold for acidic CE hydrolase activity and 5.1-fold for neutral CE hydrolase activity in the presence of acetyl LDL, suggesting that M-CSF enhanced both CE hydrolase activities to a greater extent than ACAT activity. In the absence of acetyl LDL, the ratio for neutral CE hydrolase was increased 4.9-fold by M-CSF, although M-CSF had no effect on the ratio of acidic $\mathrm{CE}$ hydrolase.

We evaluated the dose-related effects of acetyl LDL on the activity of three enzymes of macrophages (Fig. 8). ACAT and acidic $\mathrm{CE}$ hydrolase activities were induced by the addition of acetyl LDL to the culture medium, whereas the presence of acetyl LDL suppressed the activity of neutral CE hydrolase. The effects of acetyl LDL on the enzyme activities were more prominent in these experiments than in other experiments as shown in Figs. 1, 2, and 6. This discrepancy between experiments may be due to the differences in macrophages that were isolated from different donors.

Effect of $M$-CSF on CAMP content in macrophages. It has been reported that neutral $C E$ hydrolase activity is enhanced by cAMP-dependent protein kinase (12). Therefore, we evaluated the possible involvement of the cAMP-dependent pathway in the enhancement of activities of acidic and neutral CE

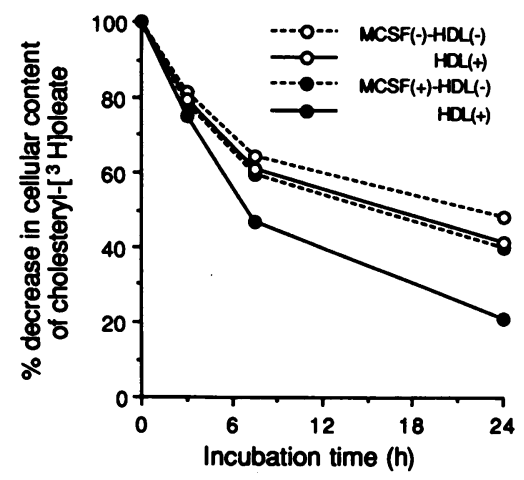

Figure 4. Hydrolysis of stored cholesteryl ester in macrophages in the presence and absence of $100 \mathrm{ng} / \mathrm{ml} \mathrm{M-CSF}$. Human monocytes were cultured for $7 \mathrm{~d}$, incubated with medium containing $50 \mu \mathrm{g} / \mathrm{ml}$ acetylated LDL and 0.2 $\mathrm{mM}\left[{ }^{3} \mathrm{H}\right.$ ]oleatealbumin for $24 \mathrm{~h}$ at $37^{\circ} \mathrm{C}$, and incubated with the same medium in the absence of lipo-

proteins for another $24 \mathrm{~h}$ at $37^{\circ} \mathrm{C}$. After washing monolayers, cells were cultured for the indicated hours without $\left[{ }^{3} \mathrm{H}\right]$ oleate-albumin in the presence or absence of $50 \mu \mathrm{g} / \mathrm{ml} \mathrm{HDL}$ and the cellular content of cholesteryl $\left[{ }^{3} \mathrm{H}\right]$ oleate was determined. Data represent the means of two different experiments, and each experiment was performed in triplicate.

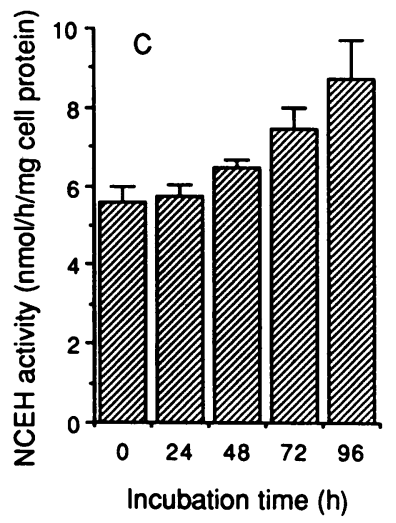

Figure 3. Time-related effects of MCSF on ACAT activity, and acidic and neutral cholesteryl ester hydrolase activities in the absence of acetyl LDL in macrophages. Human monocytes were cultured in medium containing $10 \%$ FCS without M-CSF for $7 \mathrm{~d}$. $24 \mathrm{~h}$ after incubation with serum-free medium, the cells were further cultured for the indicated hours in the presence of $100 \mathrm{ng} / \mathrm{ml}$ M-CSF. Cell homogenates were assayed for enzyme activities. Data represent the mean $\pm \mathrm{SD}$, and each experiment was performed in triplicate. hydrolases, and ACAT in response to M-CSF. As shown in Table I, $1 \mathrm{mM}$ dibutyryl cAMP significantly enhanced activity of neutral CE hydrolase in macrophages on the ninth day of culture in the absence of acetylated LDL, whereas the effect of cAMP on acidic CE hydrolase activity was not consistent and ACAT activity was not significantly influenced by cAMP. No significant effects of $100 \mathrm{nM}$ TPA on the three enzyme activities were demonstrated (Table I). When human monocytes were cultured with $1 \mathrm{mM}$ dibutyryl cAMP ( dbc AMP) for the indicated days, neutral CE hydrolase activity was enhanced in a time-related manner but no significant effect on acidic $\mathrm{CE}$ hydrolase activity was found (Fig. 9). M-CSF ( $100 \mathrm{ng} / \mathrm{ml}$ ) increased cAMP contents in macrophages in the absence of acetylated LDL (Fig. 10, $P<0.005$ at $72 \mathrm{~h}$ and $P<0.001$ at 84 and $96 \mathrm{~h}$ ). This time-related effect of M-CSF on cAMP contents was similar to the time-related changes of neutral $\mathrm{CE}$

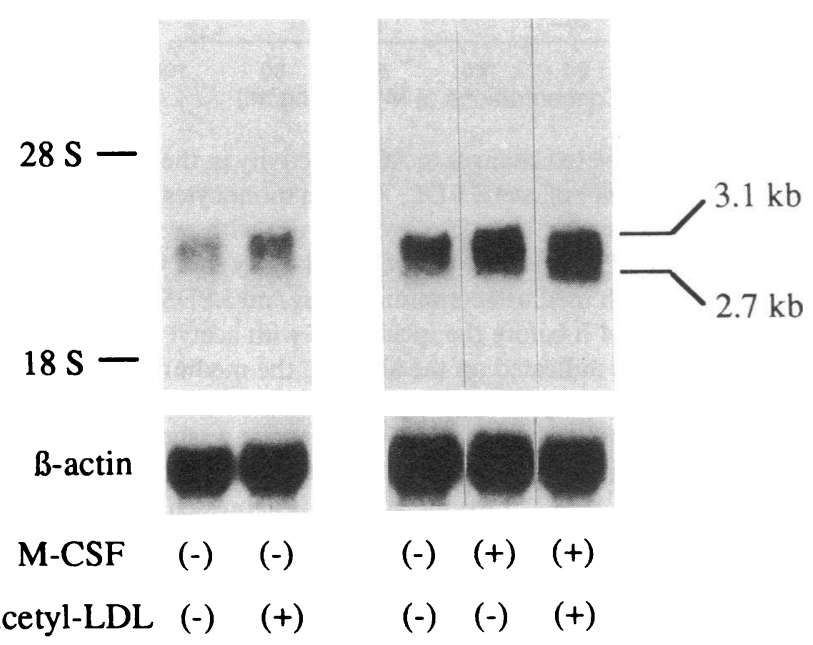

Figure 5. Northern blot analysis of acidic cholesteryl ester hydrolase mRNA isolated from human monocyte-derived macrophages. Human monocytes were cultured in medium containing $10 \%$ autologous serum with or without either $100 \mathrm{ng} / \mathrm{ml} \mathrm{M-CSF}$ or $100 \mu \mathrm{g} / \mathrm{ml}$ acetyl LDL for $9 \mathrm{~d}$. The medium was replaced every $3 \mathrm{~d}$. Total RNA was extracted from monocyte-macrophages on the last day of culture by the acid guanidium thiocyanate-phenol-chloroform method. $10 \mu \mathrm{g}$ of total RNA was electrophoretically fractionated on a $1 \%$ agarose gel and transferred to Hybond- $\mathrm{N}$ nylon membranes. The membranes were hybridized with labeled cDNA probe of either human acidic CE hydrolase or human $\beta$-actin. Two experiments were performed using macrophages isolated from two different donors. 


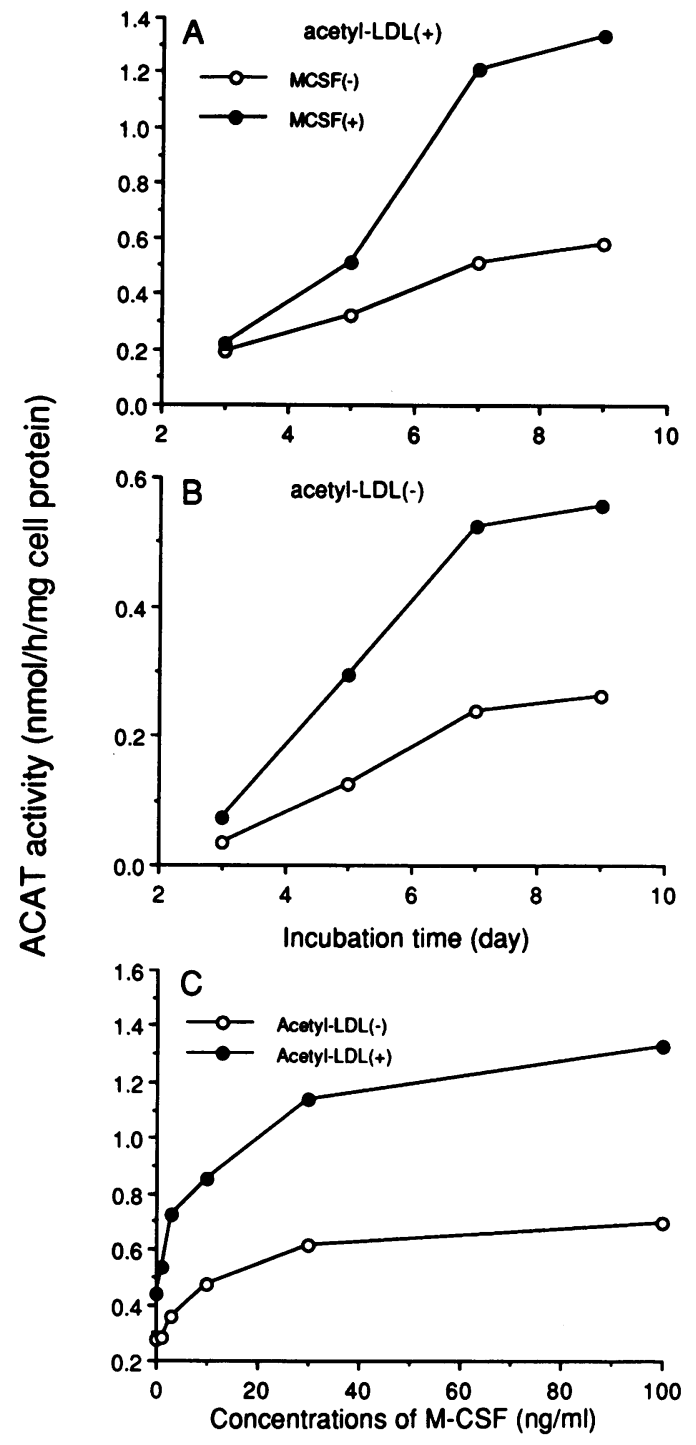

Figure 6. Time-related changes in ACAT activity in the presence (top) or absence (middle) of acetyl LDL. Human monocytes were cultured in medium containing $10 \%$ autologous serum with or without 100 $\mathrm{ng} / \mathrm{ml} \mathrm{M}$-CSF. The medium was replaced every $3 \mathrm{~d}$. Cells were preincubated with medium containing $5 \mathrm{mg} / \mathrm{ml}$ LPDS with or without M-CSF for $24 \mathrm{~h}$ before the incubation with acetyl LDL. At 24 $h$ before the time indicated on the abscissa, the medium was replaced by medium containing $100 \mu \mathrm{g} / \mathrm{ml}$ acetyl LDL with or without MCSF. After $24 \mathrm{~h}$ of incubation at $37^{\circ} \mathrm{C}$, cells were washed, scraped into buffer containing dithiothreitol, and sonicated. Cell homogenates were assayed for ACAT. Enzyme activity is expressed as nanomoles of cholesteryl $\left[{ }^{14} \mathrm{C}\right]$ oleate formed per hour per milligram cell protein. Data represent the means of two different experiments, and each experiment was performed in triplicate. Effects of M-CSF on ACAT activity in the presence or absence of acetyl LDL (bottom). Human monocytes were cultured with the indicated amounts of M-CSF for $9 \mathrm{~d}$. Cells were preincubated with medium containing $5 \mathrm{mg} / \mathrm{ml}$ LPDS for $24 \mathrm{~h}$, and then incubated with or without $100 \mu \mathrm{g} / \mathrm{ml}$ acetyl LDL for $24 \mathrm{~h}$. After $9 \mathrm{~d}$ of culture, cell homogenates were assayed for ACAT. Data represent the mean of two different experiments, and each experiment was performed in duplicate.

hydrolase activity in response to M-CSF, as shown in Fig. 3, suggesting the involvement of the cAMP-dependent pathway in the enhancement of neutral $\mathrm{CE}$ hydrolase activity in response to M-CSF.
In the presence of $100 \mathrm{ng} / \mathrm{ml} \mathrm{M}-\mathrm{CSF}, 20 \mu \mathrm{M} \mathrm{H} 89$, an inhibitor of CAMP-dependent kinase, suppressed the M-CSF-dependent increase in neutral CE hydrolase activity, whereas the effect of $\mathrm{H} 89$ on acidic CE hydrolase was minimal (Table II).

Effect of M-CSF on cholesterol efflux. We previously reported that M-CSF stimulates cholesterol efflux in human monocyte-derived macrophages, and that macrophages take up acetyl LDL to a greater extent in the presence of M-CSF than in the absence of M-CSF when incubated with the same amount of acetyl LDL (7). Since CE hydrolase and ACAT activities in macrophages were influenced by the loaded cholesteryl ester, macrophages in the presence of M-CSF were incubated with a smaller amount of acetyl LDL than those without M-CSF to obtain a similar cellular accumulation of cholesteryl ester in macrophages. Thus, in macrophages accumulating a similar amount of cholesteryl ester, we estimated the cholesterol efflux in the presence or absence of M-CSF. As shown in Fig. 11, M-CSF definitely increased the efflux of cholesteryl ester from macrophages compared with that in the absence of M-CSF.

\section{Discussion}

The activities of acidic and neutral CE hydrolase and ACAT were induced during monocyte differentiation to macrophages, and were enhanced by M-CSF. To augment these enzyme activities, monocytes were incubated for at least a few days. We have recently demonstrated that scavenger receptor activity is enhanced $2 \mathrm{~d}$ after the culture with M-CSF (7); likewise, other functions of macrophages were also enhanced by M-CSF after a long incubation period (23-26). We also reported that scavenger receptor activity is induced along with the maturation and differentiation of cells from monocytes to macrophages, whereas LDL receptor activity is diminished during their differentiation (7). M-CSF is a cytokine that stimulates the maturation and differentiation of monocyte-macrophage lineages $(1,2)$, suggesting that increased activity of the three enzymes in response to M-CSF is related to the enhanced maturation and differentiation of macrophages.

The regulation of $\mathrm{CE}$ hydrolase activities is not fully understood. Hormonal regulation of neutral CE hydrolase activity is known in some tissues $(21,27)$ and it has been reported that this enzyme activity is enhanced by cAMP-dependent protein kinase (12). We demonstrated that neutral CE hydrolase activity was enhanced by dibutyryl cAMP and inhibited by cAMPdependent protein kinase inhibitor, H89. Furthermore, we demonstrated that the time-related change of the cAMP content in macrophages in response to M-CSF was similar to that of neutral CE hydrolase activity. These results suggest that the cAMP-dependent pathway is involved in the enhancement of neutral CE hydrolase activity. On the other hand, the TPA-dependent pathways such as protein kinase $C$ were not involved in the enhancement of enzyme activities since both CE hydrolase activities were not influenced by the addition of TPA.

Increased acidic $\mathrm{CE}$ hydrolase activities have been reported in rabbit arterial foam cells (17) and rabbit atheromatous aorta (28) compared with normal aortic cells and normal aorta, respectively. On the other hand, cholesterol enrichment reduces acidic CE hydrolase activity in rabbit arterial smooth muscle cells (29). Our findings of the increased activity and mRNA level of acidic CE hydrolase in the presence of acetyl LDL support the former results that cholesterol enrichment in vascu- 

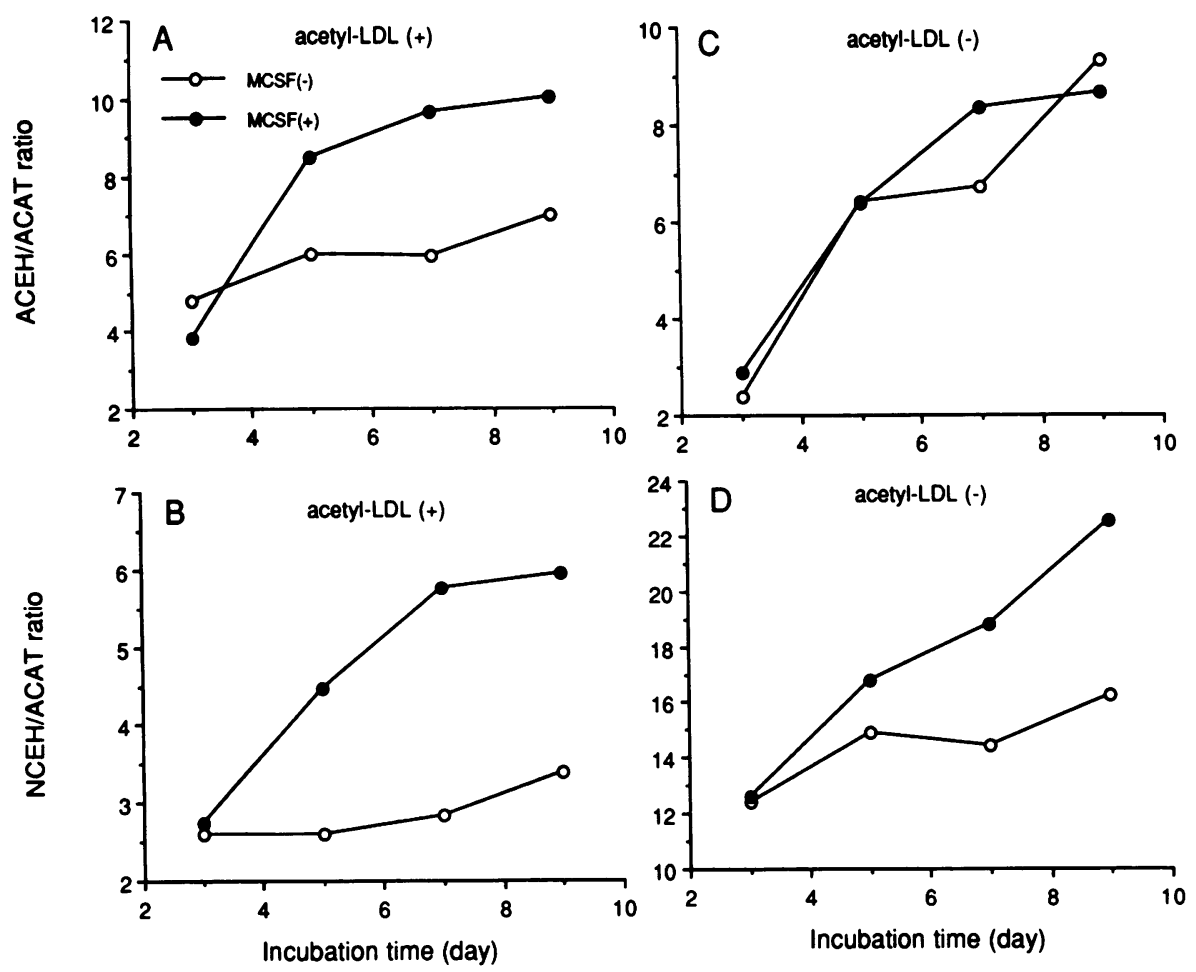

Figure 7. The effect of $100 \mathrm{ng} / \mathrm{ml} \mathrm{M}$-CSF on the ratio of acidic (top) or neutral (bottom) CE hydrolase activity per ACAT activity in the presence (right) or absence (left) of $100 \mu \mathrm{g} / \mathrm{ml}$ acetyl LDL. The ratios in the presence or absence of M-CSF were calculated from the mean data in Figs. 1 and 6.

lar cells increases the acidic CE hydrolase activity. Brown et al. suggested that neutral $\mathrm{CE}$ hydrolase activity in mouse peritoneal macrophages appears to be inhibited when cells actively
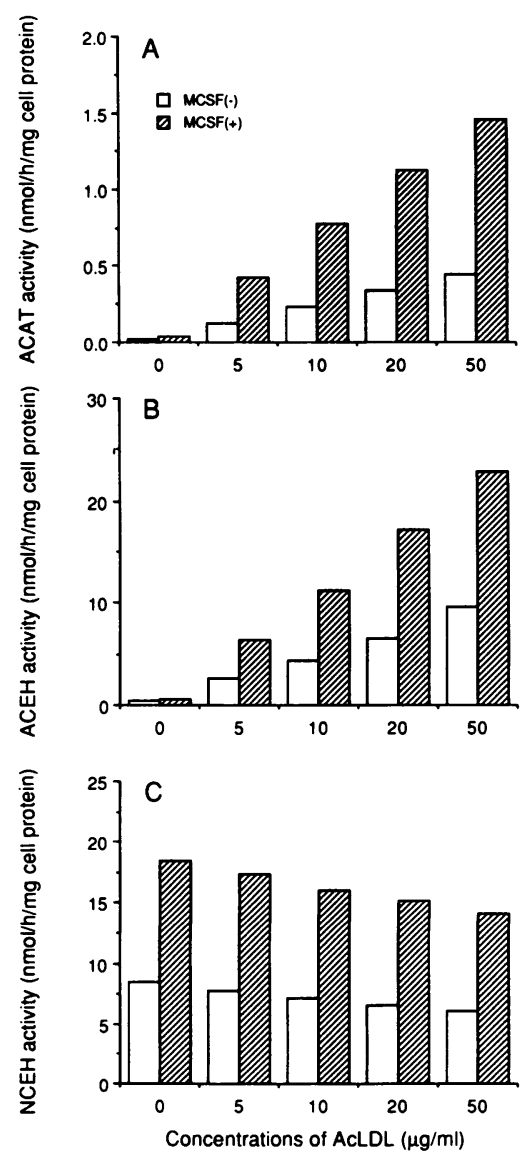
formed in triplicate.

Figure 8 . The dose-related effects of acetyl LDL on the activities of ACAT (top), acidic (middle), and neutral (bottom) CE hydrolases in the presence or absence of $100 \mathrm{ng} / \mathrm{ml} \mathrm{M}$ CSF. Human monocytes were cultured in medium containing $10 \%$ autologous serum with or without $100 \mathrm{ng} /$ $\mathrm{ml} \mathrm{M-CSF}$ for $9 \mathrm{~d}$. The medium was replaced every $3 \mathrm{~d}$. Cells were preincubated with medium containing $5 \mathrm{mg} /$ ml LPDS with or without M-CSF for $24 \mathrm{~h}$, and then incubated with the indicated amounts of acetyl LDL for $24 \mathrm{~h}$. After $24 \mathrm{~h}$ of incubation at $37^{\circ} \mathrm{C}$, cells were washed and sonicated. Cell homogenates were assayed for ACAT and acidic and neutral $C E$ hydrolases. Enzyme activities are expressed as nanomoles per hour per milligram cell protein. Data represent the take up acetyl LDL (13). This result is in accordance with the current findings demonstrating that the enzyme activity is reduced in the presence of acetyl LDL in human monocyte-derived macrophages. It is well known that ACAT activity in macrophages is enhanced when the cells accumulate an excessive amount of cholesterol (22); this was confirmed in the present study. This ACAT activity enhancement is considered to be due to the increased availability of cholesterol.

Early atherosclerosis is characterized by the presence of macrophage-derived foam cells which accumulate lipoproteincholesteryl ester. It is suggested that at least five cellular mechanisms play a role in determining the amount of cholesteryl

Table I. Effects of TPA and dbcAMP on ACAT Activity and Acidic and Neutral Cholesteryl Ester Hydrolase Activities in the Absence of Acetyl-LDL in Macrophages

\begin{tabular}{lccc}
\hline & ACEH & NCEH & ACAT \\
\hline \multicolumn{4}{c}{ nmol/hr per $m g$ cell protein } \\
Experiment 1 & & & \\
Control & $0.93 \pm 0.18$ & $5.57 \pm 0.42$ & $0.25 \pm 0.04$ \\
TPA & $1.11 \pm 0.18$ & $5.74 \pm 0.73$ & $0.27 \pm 0.03$ \\
dbcAMP & $1.42 \pm 0.24^{*}$ & $13.71 \pm 2.21^{\ddagger}$ & $0.26 \pm 0.05$ \\
Experiment 2 & & & \\
Control & $1.10 \pm 0.12$ & $5.47 \pm 0.49$ & \\
dbcAMP & $1.18 \pm 0.11$ & $8.54 \pm 0.25^{\ddagger}$ & \\
\hline
\end{tabular}

Human monocytes were cultured in medium containing 10\% FCS without M-CSF for $7 \mathrm{~d}$. $24 \mathrm{~h}$ after incubation with serum-free medium, the cells were cultured with $100 \mathrm{nM}$ TPA or $1 \mathrm{mM}$ dbcAMP for $24 \mathrm{~h}$. Cell homogenates were assayed for enzyme activities. Data represent the mean $\pm \mathrm{SD}$, and each experiment was performed in triplicate. ACEH, acidic cholesteryl ester hydrolase; $\mathrm{NCEH}$, neutral cholesteryl ester hydrolase. ${ }^{*} P<0.01 ;{ }^{\ddagger} P<0.001$; values are compared with those in the control experiment. 

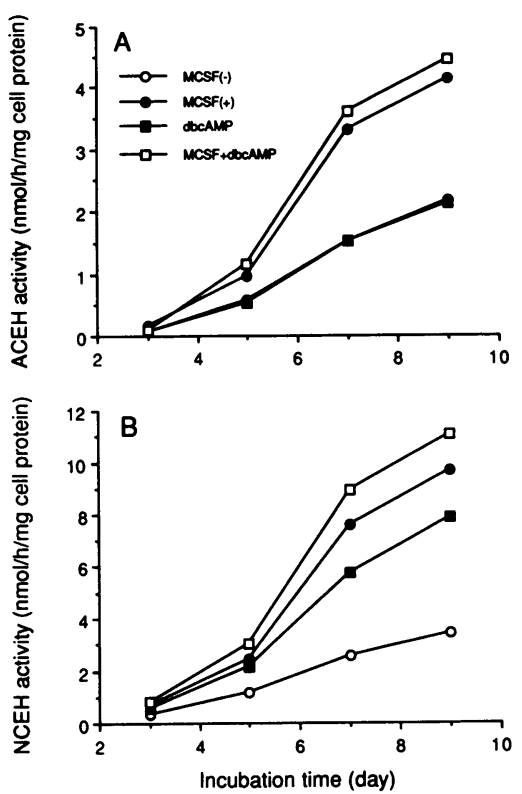

Figure 9. Time-related effects of dibutyryl cAMP on acidic (bottom) and neutral (top) cholesteryl ester hydrolase activities in the absence of acetyl LDL. Human monocytes were cultured in medium containing $10 \%$ autologous serum with or without with $1 \mathrm{mM}$ dibutyryl cAMP (dbcAMP). The medium was replaced every $3 \mathrm{~d}$. At $24 \mathrm{~h}$ before the time indicated on the abscissa, the medium was replaced by medium containing $5 \mathrm{mg}$ / ml LPDS with or without dibutyryl cAMP.

After $24 \mathrm{~h}$ of incubation at $37^{\circ} \mathrm{C}$, cells were

scraped into sucrose buffer and sonicated. Cell homogenates were assayed for acidic and neutral CE hydrolases. Enzyme activity is expressed as nanomoles of substrate hydrolyzed per hour per milligram cell protein. Data represent the means of two different experiments, and each experiment was performed in triplicate.

esters that accumulate in macrophages (13). These include: (a) the uptake of lipoprotein-cholesteryl ester through specific receptors, $(b)$ hydrolysis of lipoprotein-cholesteryl ester by a lysosomal enzyme (acidic CD hydrolase), (c) ACAT activity, $(d)$ hydrolysis of cytosolic cholesteryl ester by a nonlysosomal enzyme (neutral CE hydrolase), and (e) mediation of the active excretion of cholesterol derived from the nonlysosomal hydrolysis of cytosolic cholesteryl ester. We have recently reported that M-CSF enhances the cholesterol efflux from cholesterol-loaded macrophages without HDL (7). Cellular cholesterol efflux is regulated not only by excretion across the cell membrane, but also by activities of CE hydrolases. An increase in CE hydrolase activities as we demonstrated may represent the mechanism that explains the enhanced cholesterol efflux from macrophages in response to M-CSF.

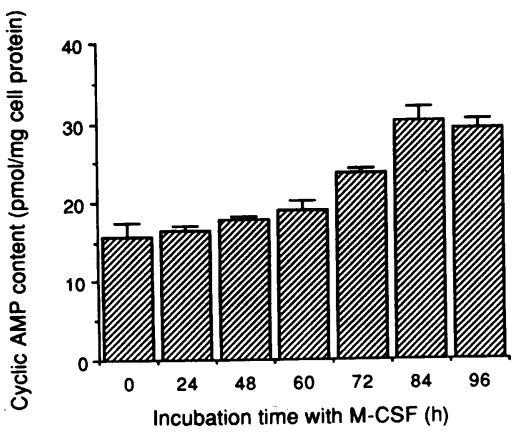

Figure 10. cAMP contents in macrophages treated with M-CSF in the absence of acetyl LDL. Human monocytes were cultured in RPMI 1640 medium containing $10 \%$ FCS for $7 \mathrm{~d}$ in the absence of M-CSF. $24 \mathrm{~h}$ after incubation with serum-free medium, the cells were further cultured for the indicated time period in the presence of $100 \mathrm{ng} /$ $\mathrm{ml}$ M-CSF. Thereafter, the cells were washed three times with ice-cold PBS and then extracted with ethanol (final 65\%). cAMP contents of triplicate wells were determined and results were expressed as mean \pm SD.
Table II. Effects of H-89 on Cholesteryl Ester Hydrolase Activities

\begin{tabular}{|c|c|c|c|c|}
\hline \multirow[b]{2}{*}{ Enzyme activity } & & \multicolumn{2}{|c|}{ H-89 } & \multirow[b]{2}{*}{$\%$ inhibition } \\
\hline & & $(-)$ & $(+)$ & \\
\hline \multicolumn{5}{|l|}{$\begin{array}{l}n m o l / h \text { per } m g \\
\text { cell protein }\end{array}$} \\
\hline \multirow[t]{3}{*}{$\operatorname{ACAT}(n=2)$} & 0 & 0.259 & 0.263 & \\
\hline & $72 \mathrm{~h}$ & 0.343 & 0.349 & \\
\hline & $\%$ increase & $32 \%$ & $33 \%$ & \\
\hline \multirow{3}{*}{$\operatorname{ACEH}(n=3)$} & 0 & $1.10 \pm 0.11$ & $1.08 \pm 0.10$ & \\
\hline & $72 \mathrm{~h}$ & $1.59 \pm 0.50$ & $1.42 \pm 0.45$ & \\
\hline & $\%$ increase & $45 \%$ & $31 \%$ & $31 \%$ \\
\hline \multirow[t]{3}{*}{$\operatorname{NCEH}(n=3)$} & 0 & $5.51 \pm 0.10$ & $5.68 \pm 0.56$ & \\
\hline & $72 \mathrm{~h}$ & $8.98 \pm 0.89$ & $6.22 \pm 0.46$ & \\
\hline & $\%$ increase & $63 \%$ & $10 \%$ & $84 \%$ \\
\hline
\end{tabular}

Human monocytes were cultured in medium containing $10 \%$ FCS without M-CSF for $7 \mathrm{~d}$. $24 \mathrm{~h}$ after incubation with serum-free medium, the cells were cultured with $100 \mathrm{ng} / \mathrm{ml}$ human M-CSF in the presence (+) or absence (-) of $20 \mu \mathrm{M}$ H-89 for $72 \mathrm{~h}$. Cell homogenates were assayed for enzyme activities. Data represent the mean of the three experiments, and each experiment was performed in triplicate. ACEH, acidic cholesteryl ester hydrolase; NCEH, neutral cholesteryl ester hydrolase.

Cellular cholesterol can undergo constant cycling between the free and ester forms when under the influence of ACAT and CE hydrolase. Lipoprotein cholesteryl ester, which is taken up by receptor-mediated endocytosis, is hydrolyzed by lysosomal acidic CE hydrolase (10). The liberated cholesterol has two fates after entering the cytoplasm: some of the cholesterol is immediately excreted, and the remainder of the cholesterol is re-esterified by the ACAT enzyme. The presence of a choles-

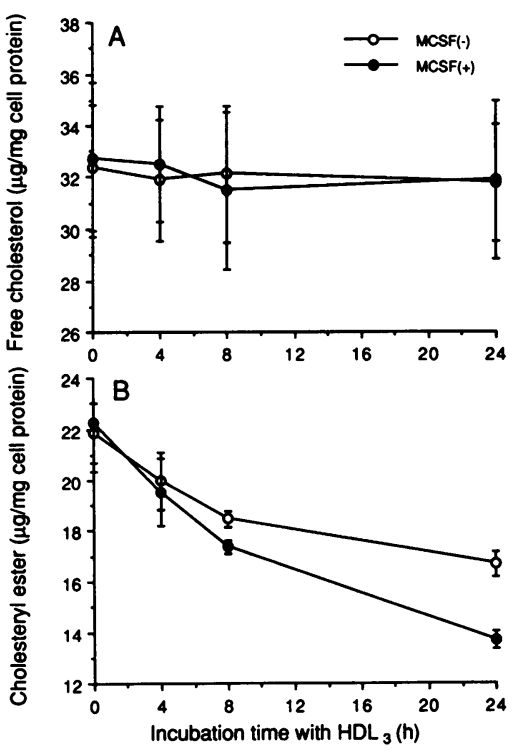

Figure 11. The effect of M-CSF on cholesterol efflux. Human monocytes were cultured in medium containing $10 \%$ autologous serum with or without $100 \mathrm{ng} /$ $\mathrm{ml}$ M-CSF for $9 \mathrm{~d}$. The medium was replaced every $3 \mathrm{~d}$. Cells were preincubated with medium containing $5 \mathrm{mg} /$ ml LPDS with or without M-CSF for $24 \mathrm{~h}$, and then incubated with $5 \mu \mathrm{g} / \mathrm{ml}$ acetyl LDL in the presence of M-CSF and with $15 \mu \mathrm{g} / \mathrm{ml}$ acetyl LDL in the absence of M-CSF for $24 \mathrm{~h}$.

After $24 \mathrm{~h}$ of incubation with acetyl LDL, the cells were incubated

with $50 \mu \mathrm{g} / \mathrm{ml} \mathrm{HDL}$ in the absence of acetyl LDL for the indicated hours with or without M-CSF. Thereafter, the cellular cholesteryl ester and free cholesterol contents were measured. Data represent the mean of three different experiments, and each experiment was performed in triplicate. 
terol acceptor in the vascular wall such as HDL or another protein interrupts this cycle, causing promotion of the net hydrolysis and subsequent excretion of the stored cholesteryl ester (30-32). This net hydrolysis is achieved by a combination of the re-esterification of cholesterol and hydrolysis of cholesteryl ester. In this study, M-CSF-enhanced activities of both ACAT and $C E$ hydrolases were observed in the presence or absence of acetyl LDL in human monocyte-derived macrophages. We therefore calculated the ratio of $\mathrm{CE}$ hydrolase to ACAT activity to estimate the net hydrolytic activity. Since we found increased ratios of both acidic and neutral $C E$ hydrolase activities to ACAT activity, it can be considered that M-CSF increased the net hydrolytic activity of cellular cholesteryl ester.

Our recent study demonstrated that M-CSF reduces the rate of atherogenesis in Watanabe heritable hyperlipidemic rabbits without a significant change in the plasma cholesterol level (14). In particular, accumulation of cholesteryl ester in the aorta was extremely low in M-CSF-treated animals, although we previously reported that M-CSF enhances not only the efflux of loaded CE but also the uptake of acetylated LDL in human monocyte-derived macrophages (7). However, we cannot directly compare the in vitro effects of M-CSF, such as the enhanced uptake of acetyl LDL, with the in vivo effect of M-CSF because it is difficult to estimate the amount of modified LDL generated in the vascular wall, which may be much less than that used in the in vitro experiments. Our in vivo results indicated that the mechanism of $\mathrm{CE}$ efflux rather than that of CE influx is relatively enhanced by M-CSF (14). Taken together with our current results, the important function of M-CSF in cellular cholesterol metabolism may be the M-CSFinduced increase in the net hydrolysis of cholesteryl ester in foam cells, which leads to the reduction of the accumulation of cholesteryl ester in the arterial wall.

\section{Acknowledgments}

We would like to thank Drs. K. Kozaki, K. Yamamoto, Y. Watanabe, and Y. Tsubamoto for their helpful discussion.

\section{References}

1. Stanley, E. R., and P. M. Heard. 1977. Factors regulating macrophage production and growth: purification and some properties of the colony stimulating factor from medium conditioned by mouse L cells. J. Biol. Chem. 252:43054312.

2. Clark, S. C., and R. Kamen. 1987. The human hematopoietic colony-stimulating factors. Science (Wash. DC). 236:1229-1237.

3. Wong, G. G., P. A. Temple, A. C. Leary, G. J. Witek, Y. C. Yang, A. B. Ciarletta, M. Chung, P. Murtha, R. Kriz, R. J. Kaufman et al. 1987. Human CSF-1: molecular cloning and expression of 4-kb cDNA encoding the human urinary protein. Science (Wash. DC). 235:1504-1508.

4. Shimano, H., N. Yamada, S. Ishibashi, K. Harada, A. Matsumoto, N. Mori, T. Inaba, K. Motoyoshi, H. Itakura, and F. Takaku. 1990. Human monocyte colony-stimulating factor enhances the clearance of lipoproteins containing apolipoprotein B-100 via both low density lipoprotein receptor-dependent and -independent pathways in rabbits. J. Biol. Chem. 265:12869-12875.

5. Mori, N., T. Gotoda, S. Ishibashi, H. Shimano, K. Harada, T. Inaba, F. Takaku, Y. Yazaki, and N. Yamada. 1991. Effects of human recombinant macrophage colony-stimulating factor on the secretion of lipoprotein lipase from macrophages. Arterioscler. Thromb. 11:1315-1321.

6. Shimano, H., N. Yamada, K. Motoyoshi, A. Matsumoto, S. Ishibashi, N. Mori, and F. Takaku. 1990. Plasma cholesterol-lowering activity of monocyte colony-stimulating factor (M-CSF). Ann. NY Acad. Sci. 587:362-370.

7. Ishibashi, S., T. Inaba, H. Shimano, K. Harada, I. Inoue, H. Mokuno, N. Mori, T. Gotoda, F. Takaku, and N. Yamada. 1990. Monocyte colony-stimulating factor enhances uptake and degradation of acetylated low density lipoproteins and cholesterol esterification in human monocyte-derived macrophages. J. Biol. Chem. 265:14109-14117.

8. Steinberg, D., S. Parthasarathy, T. E. Carew, J. C. Khoo, and J. L. Witztum.
1989. Beyond cholesterol: modifications of low-density lipoprotein that increase its atherogenicity. N. Engl. J. Med. 320:915-924.

9. Fogelman, A. M., I. Shechter, J. Seager, M. Hokom, J. S. Child, and P. Edwards. 1980. Malondialdehyde alteration of low density lipoprotein leads to cholesteryl ester accumulation in human monocyte-macrophages. Proc. Natl. Acad. Sci. USA. 77:2214-2218.

10. Takano, T., W. J. Black, T. J. Peters, and C. de Duve. 1974. Assay, kinetics, and lysosomal localization of an acid cholesteryl esterase in rabbit aortic smooth muscle cells. J. Biol. Chem. 249:6732-6737.

11. Smith, E. B., and R. H. Smith. 1976. Early changes in aortic intima. In Atherosclerosis Reviews. R. Paoletti and A. M. Gotto, Jr., editors. Raven Press New York. 119-136.

12. Khoo, J. C., E. M. Mahoney, and D. Steinberg. 1981. Neutral cholesterol esterase activity in macrophages and its enhancement by cAMP-dependent protein kinase. J. Biol. Chem. 256:12659-12661.

13. Brown, M. S., J. L. Goldstein, M. Krieger, Y. K. Ho, and R. G. W. Anderson. 1979. Reversible accumulation of cholesteryl esters in macrophages incubated with acetylated lipoproteins. J. Cell Biol. 82:597-613.

14. Inoue, I., T. Inaba, K. Motoyoshi, K. Harada, H. Shimano, M. Kawamura, T. Gotoda, T. Oka, M. Shiomi, Y. Watanabe, T. Tsukada, Y. Yazaki, F. Takaku, and N. Yamada. 1992. Macrophage colony stimulating factor prevents the progression of atherosclerosis in Watanabe heritable hyperlipidemic rabbits. Atherosclerosis. 93:245-254.

15. Inaba, T., N. Yamada, T. Gotoda, H. Shimano, M. Shimada, K. Momomura, T. Kadowaki, K. Motoyoshi, T. Tsukada, N. Morisaki et al. 1992. Expression of M-CSF receptor encoded by c-fms on smooth muscle cells derived from arteriosclerotic lesion. J. Biol. Chem. 267:5693-5699.

16. Ishibashi, S., N. Yamada, H. Shimano, N. Mori, H. Mokuno, T. Gotohda M. Kawakami, T. Murase, and F. Takaku. 1990. Apolipoprotein E and lipoprotein lipase secreted from human monocyte-derived macrophages modulate very low density lipoprotein uptake. J. Biol. Chem. 265:3040-3047.

17. Haley, N. J., S. Fowler, and C. de Duve. 1980. Lysosomal acid cholesteryl esterase activity in normal and lipid-laden aortic cells. J. Lipid Res. 21:961-969.

18. Lowry, O. H., N. J. Rosebrough, A. L. Farr, and R. J. Randall. 1951. Protein measurement with the Folin phenol reagent. J. Biol. Chem. 193:265275.

19. Anderson, R. A., and G. N. Sando. 1991. Cloning and expression of cDNA encoding human lysosomal acid lipase/cholesteryl ester hydrolase: similarities to gastric and lingual lipases. J. Biol. Chem. 266:22479-22484.

20. Gotoda, T., N. Yamada, M. Kawamura, K. Kozaki, N. Mori, S. Ishibashi, H. Shimano, F. Takaku, Y. Yazaki, Y. Furuichi, and T. Murase. 1991. Heterogeneous mutations in the human lipoprotein lipase gene in patients with familial lipoprotein lipase deficiency. J. Clin. Invest. 88:1856-1864.

21. Hajjar, D. P., C. R. Minick, and S. Fowler. 1983. Arterial neutral cholesteryl esterase: a hormone-sensitive enzyme distinct from lysosomal cholesteryl esterase. J. Biol. Chem. 258:192-198.

22. Brown, M. S., Y. K. Ho, and J. L. Goldstein. 1980. The cholesteryl ester cycle in macrophage foam cells: continual hydrolysis and re-esterification of cytoplasmic cholesteryl esters. J. Biol. Chem. 255:9344-9352.

23. Warren, M. K., and P. Ralph. 1986. Macrophage growth factor CSF-1 stimulates human monocyte production of interferon, tumor necrosis factor, and colony stimulating activity. J. Immunol. 137:2281-2285.

24. Magee, D. M., E. J. Wing, N. M. Ampel, A. Waheed, and R. K. Shadduck. 1987. Macrophage colony-stimulating factor enhances the expression of Fc receptors on murine peritoneal macrophages. Immunology. 62:373-378.

25. Munn, D. H., and N. K. Cheung. 1989. Antibody-dependent antitumor cytotoxicity by human monocytes cultured with recombinant macrophage colony-stimulating factor. Induction of efficient antibody-mediated antitumor cytotoxicity not detected by isotope release assays. J. Exp. Med. 170:511-526.

26. Motoyoshi, K., K. Yoshida, K. Hatake, M. Saito, Y. Miura, N. Yanai, M. Yamada, T. Kawashima, G. G. Wong, P. A. Temple et al. 1989. Recombinant and native human urinary colony-stimulating factor directly augments granulocytic and granulocyte-macrophage colony-stimulating factor production of human peripheral blood monocytes. Exp. Hematol. (NY). 17:68-71.

27. Behrman, H. R., and D. T. Armstrong. 1969. Cholesterol esterase stimulation by luteinizing hormone in luteinized rat ovaries. Endocrinology. 85:474480.

28. Brecher, P., H. Y. Pyun, and A. V. Chobanian. 1977. Effect of atherosclerosis on lysosomal cholesterol esterase activity in rabbit aorta. J. Lipid Res. 18:154-163.

29. Pomerantz, K. B., and D. P. Hajjar. 1990. High-density-lipoprotein-induced cholesterol efflux from arterial smooth muscle cell derived foam cells: functional relationship of the cholesteryl ester cycle and eicosanoid biosynthesis. Biochemistry. 29:1892-1899.

30. Oram, J. F. 1983. Effects of high density lipoprotein subfractions on cholesterol homeostasis in human fibroblasts and arterial smooth muscle cells. Arteriosclerosis. 3:420-432.

31. Hara, H., and S. Yokoyama. 1991. Interaction of free apolipoproteins with reduction of cellular cholesterol. J. Biol. Chem. 266:3080-3086.

32. Basu, S. K., J. L. Goldstein, and M. S. Brown. 1983. Independent pathways for secretion of cholesterol and apolipoprotein $\mathrm{E}$ by macrophages. Science (Wash. DC). 219:871-873. 